\title{
Initial Phase of Epigenetic Pathways in Carcinogenesis and Mutagenesis
}

\author{
Marvin Melzer*
}

*Corresponding author: Marvin Melzer, 3430 Relford Street, Cincinnati, Ohio 45220, USA, Tel: 5139615425; E-mail: msmelszer16@hotmail.com

Received date: Apr 29, 2014, Accepted date: Jun 30, 2014, Published date: Jul 05, 2014

Copyright: (c) 2014 Melzer M. This is an open-access article distributed under the terms of the Creative Commons Attribution License, which permits unrestricted use, distribution, and reproduction in any medium, provided the original author and source are credited.

\section{Mini- Review}

Epigenetic pathway is one of the major routes to carcinogenesis. A key enzyme involved in this pathway is DNA-MTase (DMT). There are evidences that carcinogens cause an increase in the activity of this enzyme. The increased activity is due to an increase in transcriptional control of the three forms of the enzyme, Dnm1, Dnm3a and Dnm3b [1]. The general function of DMTs was described by Berletch et al. [2]. The enzyme catalyses the transfer of methyl groups from 5adenoxylmethionine (SAM) to $\mathrm{GpC}$ islands in key protein binding sites of DNA. The essential function of DMTs is to methylate the CpG islands in cancer suppressor genes, thus inactivating these suppressor genes and enabling the expression of cancer associated genes and thereby allowing the carcinogenic process to occur [3-5]. In normal cells, most CpG sequences are methylated but there are still $15 \%$ of which are not methylated, the CpG sequences are clustered in 20,000 regions called $\mathrm{CpG}$ islands which are not methylated. Aberrant methylation leads to cancer [5]. That is DMT is the key that opens the door to a major pathway leading to cancer.

DMT has a role not only in carcinogenesis but in mitogenesis as well. Yang et al. [6] showed that the action of mitogens on T-cells involves DNA methylation. In fact, epigenetic pathways may be involved in the expression of the mitogens themselves [7]. Warburton et al. [8] reported that epigenetic pathways are involved in the action of EGF on embryo cells. Hypomethylation is involved in atherosclerosis lesions, and such hypomethylation gives rise to the increased DNA synthesis in these lesions [9].

Carcinogens have been found to increase expression of DMT. Ge et al. [10] reported that Wy-14643, a carcinogen, induces hypomethylation of the c-myc oncogene which promoted the expression of c-myc. They also reported that the activity of DMT is increased by this enzyme. As we reported in our earlier paper [11], overexpression of c-myc is a characteristic of cancer. It was found that cigarette smoking causes the hypermethylation of the p161NK4-alpha gene in lung cancer patients [12]. Hammonds et al. [13] reported that in fact smoking increases expression of hepatic DMT. Carcinogen treatment increases expression of DMT as an early event in carcinogenesis. Tabish et al. [14] showed that carcinogens such as benzene, hydroquinone, styrene, carbon tetrachloride and trichloethylene caused DNA methylation, presumably mediated by DMT. Belinsky et al. [15] showed that carcinogen treatment results in an increase in cytosine DNA-methyltransferase in target cells and this is an early event in lung cancer induced by carcinogen.

The question that has up to now been left unanswered is just how does a carcinogen induce expression of the gene coding for DMT?. It is the aim of this paper to offer a series of events that describe the mechanism whereby carcinogens can induce expression of oncogenic genes in general and DMT gene in particular.

In another of our earlier papers [16] we reviewed the extensive evidence that endocytosis and action at the lysosomal level is essential for carcinogen action. This evidence consisted of findings that inhibition of lysosomal degradation of proteins blocked the carcinogenic process. Cathepsin inhibitors such as leupeptin, antipain, etc. were used in these studies, The same situation applies to mitogenesis induced by various growth factors [17-23]. These growth factors operate by receptors on the cell membrane. Estrogen is a carcinogen [24]. As reviewed in an earlier publication by this author [25], there is much emerging evidence that estrogen too exerts its action via receptors on the cell membrane and that endocytosis plays a vital role in the action of sex hormones.

Thus we come to the first event when a carcinogen or a mitogen attacks its target cell: An endocytic process occurs resulting in delivery of the carcinogen-(cell membrane) receptor complex (Ca-Re) or the mitogen-receptor complex (Mi-Re) to the lysosome where the complex undergoes degradation into di and tripeptides.

What could this endocytic process, this degradation of mitogen or carcinogen receptors, play a role in the carcinogenic or mitogenic process? To answer this question we have some clues:

1. It is known that some genes are usually, in the absence of inducing agent, are repressed by protein repressors.

2. It is also known that there is specificity in the action of small peptides on proteins [26-28]. This opens the possibility that small peptides, produced on degradation of endocytosed Mi - Re or CaRe interact very specifically with proteins comprising gene repressors. It is quite conceivable that such an interaction can cause a change in the conformation of the repressors such that it can no longer bind to its cognate gene. That is these small peptides, acting in a very specific manner, displace the repressor from its gene. This releases the gene for expression. Tp summarize our proposal in equations:

$\mathrm{Re}-+\mathrm{Ca}($ or $\mathrm{Mi})=\mathrm{Re}-\mathrm{Ca}($ or $\mathrm{Mi}-\mathrm{Re})$

$\mathrm{Ca}-\mathrm{Re}($ or $\mathrm{Mi}-\mathrm{Re})=$ lysosomal proteases (i.e.cathepsins) $=$ mixtures of di-and tripeptides.

These small peptides (with the aid of specific permeases), on formation leave the lysosomes and enter the nucleus. There they bind to various repressor proteins to liberate the Gene $(\mathrm{Ge})$ for expression. That is: $\mathrm{Ge}=$ gene; $\mathrm{Rp}=$ repressor

Small peptide (formed in lysosomes as described above) + Ge-Rp $=$ small peptide $-\mathrm{Rp}+\mathrm{Ge}$ (free for expression).

As can be seen from our proposal, small peptides formed from degradation (by lysosomal cathepsins) of endocytosed mitogen-(or carcinogen)-receptor complexes might actually have important determinants of just which genes are to be expressed and which will remain repressed, on treatment with either a carcinogen or a noncarcinogenic mitogen (growth factor).

That leads to another concept: The identity of the genes that are derepressed (divested of repressor, thus activated) and which remain 
Page 2 of 3

repressed is determined by the nature of the small peptides produced in the endocytic process described above. This is determined by the following factors:

1. The nature of the proteases in the target cell. It was shown by Tanji [29]. That there are different cathepsin $\mathrm{D}$ isoforms and that these cathepsin $\mathrm{D}$ isoforms each has a different specificity. That is each isoform of cathepsin $\mathrm{D}$ cleaves a protein at a different peptide linkage. This will yield a different collection of small peptides formed when each isoform acts on endocytsed Mi-Re or Ca-Re complex. What determines which isoform of cathepsin D will be present in a target cell? It is not unreasonable to propose that heredity might well determine which isoform will be present in cells treated with any cytokine, that is that there is a hereditary polymorphism among cathepsins $[30,31]$.

2. The nature of the receptors. Here again there is polymorphism such as that observed in the case of T-cell receptors [32,33]. It seems apparent that with a different substrate for the lysosomal proteases, a different set of small peptide fragments will be formed on degradation of the endocytosed receptor.

Thus one cell, cell A, equipped with one isoform of the cytokine receptor and one isoform of cathespin in its lysosomes will produce a particular set of small peptide gene derepressors, compared with another cell (in another organism) (cell B) will produce another set of small peptide gene activators. In one case (cell A) (cell B) the activators so formed (as fragments or an endocytosed cytokine receptor) will contain all the small peptides (di-and tripeptides)need to derepress all the oncogenes needed to initiate and develop a cancer while another cell (Cell B) may not be so endowed.

Cell A will become transformed into a clinical cancer (a neoplasia) while cell B may (depending on the nature of the small peptides produced in the endocytic process described above might) just produce a hyperplasia. Thus whether a cell will be transformed by an agent will be determined on the nature of the small peptides produced on degradation (in lysosomes) of its endocytosed agent-receptor complex, and this in turn is determined by the nature of its receptor and the nature of its lysosomal proteases (i.e. which receptor isoform and which cathepsin isoform is present in the target cell). This in turn is probably determined by hereditary factors.

What does all this have to do with DNA-MTase, which is the subject of this paper? From the above discussion, a possible answer emerges: In a cell destined to enter the epigenetic pathway to carcinogenesis or mitogenesis there is produced a set of small peptides which are capable of causing the repressors of the DMT gene to dissociate from the gene and thus induce the transcription of that gene or set of genes that give rise to DMT. In a cell destined to undergo carcinogenesis all the other oncogenes needed to form a cancer are activated while in a cell destined to undergo non-carcinogenic mitogenesis degradation of endocytosed agent-receptor complexes fail to produce those small peptides needed to derepress all the oncogenes (including perhaps the gene(s) coding for DMT) needed to give rise to a cancer. They produce merely a hyperplastic rather than a neoplastic situation.

This proposed mechanism therefore, in sum, answers the questions:

1) What is the role of endocytosis and lysosomal protease in the action of carcinogens and mitogens?

2) What role can small peptides produce effects on gene expression?
3) How can a carcinogen or a mitogen cause there to be increased m-RNA for DMT in treated cells?

4) How can hereditary factors determine whether an agent will produce hyperplasia in one cell (or one organism) and produce a neoplasia in another cell or even remain unchanged?

To test the above concepts, the following experiments might be performed.

Determine if in fact lysosomal protease inhibitors (including leupeptin, methylamine, antipain, etc.) inhibit production of DMT mRNA in carcinogen treated cells.

Determine the presence of any proteins on the cell surface of cells known to be transformed by a particular agent which form a complex with the transforming agent.

Determine if there are any differences in carcinogen cell surface receptors and among the endolysosomal proteases between a cell line that is transformed compared with a cell line that is not transformed.

The above proposed series of events producing DMT might well be testable.

NOTE: That small peptides can regulate specific gene expression is not unprecedented. Indeed there have been reported some examples of specific small peptides activating specific genes [34-36]. In view of these reports it is not unreasonable to propose, as suggested by the mechanism offered in this paper, that small peptides obtained by degradation of endocytosed agent-receptor complexes could act in a similar manner: activating(by divesting genes of their repressors) genes giving rise to new cell growth, including the gene(s) coding for DMT.

\section{References}

1. Casillas MA Jr, Lopatina N, Andrews LG, Tollefsbol TO (2003) Transcriptional control of the DNA methyltransferases is altered in aging and neoplastically-transformed human fibroblasts. Mol Cell Biochem 252: 33-43.

2. Berletch JB, Phipps SM, Walthall SL (2007) A method to study the expression of DMTs in aging cells in vitro. Methods in Mol Biol 37: 81-87

3. Li JS, Ying JM, Wang XW, Wang ZH, Tao Q, et al. (2013) Promoter methylation of tumor suppressor genes in esophageal squamous cell carcinoma. Chin J Cancer 32: 3-11.

4. Hatada I (2006) Emerging technologies for genome-wide DNA methylation profiling in cancer. Crit Rev Oncog 12: 205-223.

5. Chatterjee R, Vinson C (2012) CpG methylation recruits sequence specific transcription factors essential for tissue specific gene expression. Biochim Biophys Acta 1819: 763-770.

6. Yang J, Deng C, Hemati N, Hanash SM, Richardson BC (1997) Effect of mitogenic stimulation and DNA methylation on human T cell DNA methyltransferase expression and activity. J Immunol 159: 1303-1309.

7. Lee CG, Sahoo A, Im SH (2009) Epigenetic regulation of cytokine gene expression in T lymphocytes. Yonsei Med J 50: 322-330.

8. Warburton D, Seth R, Shum L, Horcher PG, Hall FL, et al. (1992) Epigenetic role of epidermal growth factor expression and signalling in embryonic mouse lung morphogenesis. Dev Biol 149: 123-133.

9. Hiltunen MO, Turunen MP, Häkkinen TP, Rutanen J, Hedman M, et al. (2002) DNA hypomethylation and methyltransferase expression in atherosclerotic lesions. Vasc Med 7: 5-11.

10. Ge R, Wang W, Kramer PM, Yang S, Tao L, et al. (2001) Wy-14643 induced hypermethylation of the c-mcy gene in mouse liver. Toxicol.Sci: 128-136 
Citation: Melzer M (2014) Initial Phase of Epigenetic Pathways in Carcinogenesis and Mutagenesis. J Carcinog Mutagen 5: 180. doi: $10.4172 / 2157-2518.1000180$

Page 3 of 3

11. Melzer MS (2012) Amino acid-anticodon binding specificity: rationale for a new class of therapeutic agent. Drug Discov Today 17: 291-295.

12. Zhang B, Zhu W, Yang P, Liu T, Jiang M, et al. (2011) Cigarette smoking and p16INK4 1 I gene promoter hypermethylation in non-small cell lung carcinoma patients: a meta-analysis. PLoS One 6: e28882.

13. Hammonds GJ, Yan Y, Lopatina NC (1999) Increased expression of hepatic DMT in smokers. Cell Biol.Toxicol 15: 388-399

14. Tabish AM, Poels K, Hoet P, Godderis L (2012) Epigenetic factors in cancer risk: effect of chemical carcinogens on global DNA methylation pattern in human TK6 cells. PLoS One 7: e34674.

15. Belinsky SA, Nikula KJ, Baylin SB, Issa JP (1996) Increased cytosine DNA-methyltransferase activity is target-cell-specific and an early event in lung cancer. Proc Natl Acad Sci U S A 93: 4045-4050.

16. Melzer MS (2011) Role of the endocytic pathway in carcinogenesis. Toxicology 283: 151-156.

17. Saito M, Hagiwara T, Aoyagi T, Nagai Y (1972) Leupeptin, a protease inhibitor, inhibits the PHA-stimulated DNA synthesis in guinea pig blood lymphocytes. Jpn J Exp Med 42: 509-511.

18. Legrue SJ, Sheu TL, Chernajovsky Y (1991) The role of receptor-ligand endocytosis and degradation in interleukin-2 signaling and Tlymphocyte proliferation. Lymphokine Cytokine Res 10: 431-436.

19. Shau H, Dawson JR (1985) Regulation of human natural killing by lysosomotropic and thiol-reactive agents. Immunology 55: 647-654.

20. Tchórzewski H, Fornalczyk E, Paśnik J (1995) Protease inhibitors diminish lymphocyte stimulation in vitro. Immunol Lett 46: 237-240.

21. Duprez V, Ferrer M, Cornet V, Olive D, Dautry-Varsat A (1991) Modulation of interleukin 2 internalization and interleukin 2-dependent cell growth by antireceptor antibodies. J Biol Chem 266: 1497-1501.

22. Kumar A, Moreau JL, Gibert M, Thèze J (1987) Internalization of interleukin 2 (IL-2) by high affinity IL-2 receptors is required for the growth of IL-2-dependent T cell lines. J Immunol 139: 3680-3684.

23. King AC, Hernaez-Davis L, Cuatrecasas P (1981) Lysosomotropic amines inhibit mitogenesis induced by growth factors. Proc Natl Acad Sci U S A 78: 717-721.

24. Kennedy AR, Weichselbaum RR (1981) Effects of 17 beta-estradiol on radiation transformation in vitro; inhibition of effects by protease inhibitors. Carcinogenesis 2: 67-69.

25. Melzer M (2012) Lysosomes, growth factor activity, and carcinogenic implications. Crit Rev Eukaryot Gene Expr 22: 345-358.
26. Fenton C, Hansen A, el-Gewely MR (1998) Modulation of the Escherichia coli tryptophan repressor protein by engineered peptides. Biochem Biophys Res Commun 242: 71-78.

27. Payne JW, Grail BM, Gupta S, Ladbury JE, Marshall NJ, et al. (2000) Structural basis for recognition of dipeptides by peptide transporters. Arch Biochem Biophys 384: 9-23.

28. Pierschbacher MD, Ruoslahti E (1987) Influence of stereochemistry of the sequence Arg-Gly-Asp-Xaa on binding specificity in cell adhesion. J Biol Chem 262: 17294-17298.

29. Tanji M, Kageyama T, Takahashi K (1991) Occurrence of cathepsin D isozymes with different specificities in monkey skeletal muscle. Biochem Biophys Res Commun 176: 798-804.

30. Lefèvre C, Blanchet-Bardon C, Jobard F, Bouadjar B, Stalder JF, et al. (2001) Novel point mutations, deletions, and polymorphisms in the cathepsin $\mathrm{C}$ gene in nine families from Europe and North Africa with Papillon-Lefèvre syndrome. J Invest Dermatol 117: 1657-1661.

31. Sutton VR, Trapani JA (2010) Proteases in lymphocyte killer function: redundancy, polymorphism and questions remaining. Biol Chem 391: 873-879.

32. Usuku K, Joshi N, Hauser SL (1992) T-cell receptors: germline polymorphism and patterns of usage in demyelinating diseases. Crit Rev Immunol 11: 381-393.

33. Gras S, Chen Z, Miles JJ, Liu YC, Bell MJ, et al. (2010) Allelic polymorphism in the $\mathrm{T}$ cell receptor and its impact on immune responses. J Exp Med 207: 1555-1567.

34. Morikawa K, Ishikawa K, Kanamaru Y, Hori G, Nagaoka S (2007) Effects of dipeptides having a C-terminal lysine on the cholesterol 7alphahydroxylase mRNA level in HepG2 cells. Biosci Biotechnol Biochem 71: 821-825.

35. Ohara H, Ichikawa S, Matsumoto H, Akiyama M, Fujimoto $\mathrm{N}$, et al. (2010) Collagen-derived dipeptide, proline-hydroxyproline, stimulates cell proliferation and hyaluronic acid synthesis in cultured human dermal fibroblasts. J Dermatol 37: 330-338.

36. Papadopoulos V, Dym M (1994) Sertoli cell differentiation on basement membrane is mediated by the c-fos protooncogene. Proc Natl Acad Sci U S A 91: 7027-7031. 